\title{
Conceptualizing Smart Manufacturing Readiness-Maturity Model for Small and Medium Enterprise (SME) in Malaysia
}

\author{
Syed Radzi Bin Rahamaddulla ${ }^{1,2, * \mathbb{C}}$, Zulkiflle Leman ${ }^{1}$, B. T. Hang Tuah Bin Baharudin ${ }^{1}(\mathbb{C}$ \\ and Siti Azfanizam Ahmad ${ }^{1}$ \\ 1 Department of Mechanical and Manufacturing Engineering, Faculty of Engineering, Universiti Putra \\ Malaysia, Serdang 43400, Malaysia; zleman@upm.edu.my (Z.L.); hangtuah@upm.edu.my (B.T.H.T.B.B.); \\ s_azfanizam@upm.edu.my (S.A.A.) \\ 2 Fakulti Teknologi Kejuruteraan Pembuatan Dan Mekatronik, Universiti Malaysia Pahang, \\ Pekan 26600, Malaysia \\ * Correspondence: syedradzi@gmail.com
}

Citation: Rahamaddulla, S.R.B.; Leman, Z.; Baharudin, B.T.H.T.B.; Ahmad, S.A. Conceptualizing Smart Manufacturing Readiness-Maturity Model for Small and Medium Enterprise (SME) in Malaysia. Sustainability 2021, 13, 9793. https:// doi.org/10.3390/su13179793

Academic Editor: Vladimir Strezov

Received: 11 August 2021

Accepted: 25 August 2021

Published: 31 August 2021

Publisher's Note: MDPI stays neutral with regard to jurisdictional claims in published maps and institutional affiliations.

Copyright: (c) 2021 by the authors. Licensee MDPI, Basel, Switzerland. This article is an open access article distributed under the terms and conditions of the Creative Commons Attribution (CC BY) license (https:// creativecommons.org/licenses/by/ $4.0 /)$.

\begin{abstract}
Manufacturing enterprises today are forced to face radical challenges in the disruptive concepts of Smart Manufacturing (SM) and Industry 4.0 to stay competitive. Most Multinational Enterprise (MNEs) have initiated their journey towards adopting SM. As a mainspring of many manufacturing economies, Small and Medium-Enterprise (SMEs) are still struggling to understand the complexity offered in SM, and many of them are not ready to embrace the concept of SM. To overcome this, SMEs first need to assess their readiness and maturity before embarking on an SM journey. The existing available readiness assessment model seems to be suitable for MNEs, and there is still a lack of tailored models that suit SMEs. This paper sought to pinpoint the conceptual framework from the review of the existing readiness-maturity assessment and identify the gap of existing model as well as proposed a tailored model framework that are suitable for SMEs. Ultimately, this model will be used to pursue a comprehensive scholarly study across Malaysia. The proposed model is enhanced with $4 \mathrm{M}$ attributes as the dimension and embedded with the characteristic of Industry 4.0 build component to help the SME's overcome the possible uncertainties in adopting SM concept.
\end{abstract}

Keywords: Smart Manufacturing (SM); Industry 4.0; smart factory; readiness assessment; maturity model; technology readiness; Small-Medium Enterprise (SME)

\section{Introduction}

Industry 4.0 is an advanced strategy introduced by the German government to promote the integration of diverse technologies that make manufacturing process smarter [1-6]. For instance, the technologies such as the Internet of Things (IoT), Internet of Service (IoS), social product development, Enterprise Resource Planning (ERP), and radio frequency identification (RFID) have been widely implemented to achieve smarter production system. The combination of this technology will foster mass customization, inexpensive product planning, accurate control of the manufacturing process, condition base maintenance, as well as the automated manufacturing process [7-9].

These technological trends are designed to facilitate machine to machine (M2M) communication using minimal to null dependence on human force. Industry 4.0 transform processes, operations, machinery, supply chain management, and the entire energy footprint of manufacturing enterprises. It also enhances and monitors the after-purchase performance such as maintenance and servicing. At the global front, manufacturing enterprises are already exploring the limitless possibilities of Industry 4.0 and are reimagining the future. The traditional manufacturing processes and machinery are undergoing digitization and technological transformation to accelerate efficiency, flexibility, and speed to survive the fierce market competition. 


\subsection{Digitalization Transformation towards the Industrial Revolution}

Digital technology perceived as a mixed match of information, computing, communications, and connectivity technologies [10]. Digitalization will ensure that the manufacturing business runs efficiently, responsively, and cost-effectively [11]. In a holistic approach, digitalization is an enabler for a vertical (within the company) and horizontal (between companies) integration. Monostori et al. [12] and Nick et al. [13] reiterated that the vision of Industry 4.0 should have these four goals:

1. Vertical integration: In a smart factory system, a digital model communicates via the cyber-physical system, which comprises people, machines, and resources, is mapped.

2. Horizontal integration: The smart factory adapts itself to the surrounding system as it can optimize the entire production process in real-time.

3. Smart product: The ability to retrieve product lifecycle information that will add to the digital modelling of the smart factory and offer a better product-based service.

4. Human Being: The focal point and the driver of valued addition to the entire chain.

With the relationship between the service provider, supplier, and customer becoming integrated, a stand-alone automation manufacturing system is becoming an isolated choice [13]. Such a system has its limitation within the organization $[1,11]$. The disapproval of the stand-alone automation system is also due to the rising concern on interoperability between machines. The inability to communicate vertically and horizontally in Industry 4.0 offers the ideal answer for the misalignment between automation technologies. With the ability to interact with each other, the Cyber-Physical System (CPS) and the Internet of Things (IoT) are the missing puzzle pieces for the stand-alone automation solution [14]. Thus, integrating the philosophy of Industry 4.0 will help manufacturing businesses leap forward, and this involves strategical decisions due to the enormous investments that need to be made.

Many success stories have been attained from the significance of the digital transformation of an organization [10,15]. Digital technologies are viewed as a tool that profoundly eases the transformation of business strategies, processes, capabilities, the way their customers are served, and their product offerings. Digitalization is in line with Industry $4.0[16,17]$. Nevertheless, embracing digitalization is not an easy task and can become complicated at times. A survey done by the Harvard Business Review [18] encompasses that corporate and people's culture, process and technologies of the organization are directly influencing the transformation process. Henceforth, the manufacturing enterprises needs to emphasize further the assimilation of inclusive knowledge and technology transfer [19].

\subsection{Industry 4.0 Pillars in Crafting Smart Manufacturing (SM)}

In line with Industry 4.0, Smart Manufacturing (SM) employs computer-integrated manufacturing, high levels of adaptability and rapid design changes, digital information technology, and more flexible technical workforce training [17]. Throughout the first industrial revolution to this date, other industrial revolutions have been driven by automation and digital transformation. Following the revolutions' trends, a smarter manufacturing system that is integrated with robots and sensors is expected to play a pivotal role in next-generation manufacturing.

With the birth of 5G technology, machines can interact, visualize the production chain, and make a crucial decision accurately and timely. Industry 4.0 is being backed by the combination of several new technology enablers as well with some existing technological apparatuses. Visibly, SM is a repackage of the combination of capabilities and technologies that serve as the pillar in making SM happen. The IoT, robotics, cloud computing, big data analytics, virtual reality, system integration, additive manufacturing, cyber security, and cyber-physical system are the pillars of the Industrial Revolution 4.0 [20-25]. 


\subsection{Smart Manufacturing}

Today's manufacturing is getting more complicated [26,27]. The term SM and Industry 4.0 expound the same reference meaning. In the United States of America, "smart

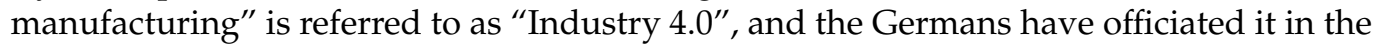
Hannover Fair in the year 2011. Similarly, the Koreans refer to the term "Industry 4.0" as a "Smart Factory". Regardless of the terminology, these three terms signify the key goal of improving businesses and their manufacturing environments in diverse countries to connect and embrace the narrative of technological advancement in the information and operation technologies. This noble aim is expected to facilitate steady income flows with the associated cost reduced and efficacy gains.

Lasi et al. [16] explained that to reduce operating costs, the prospect of future production is no longer dependent on batch order. This phenomenon has changed, and the manufacturer needs to think about smarter alternatives to meet customer-driven batch sizes while retaining mass production economies. As a driving force, intelligent sensors, intelligent solutions, innovative technologies, and the Internet and the Cloud are proven to promote digitalization and automation. Such disruptive developments of the technology enable product development time to be fostered and customization and versatility to be encouraged.

A smart factory consists of integrated systems from various components within a factory that makes the entire factory system more flexible and reconfigurable Wang et al. [28]. The smart factory system integrates and connects the industrial network via the cloud and supervisory control terminals with smart shop floor object that leads to autonomous decision making. This was primarily to develop a smarter and higher-efficiency factory systems. Without cloud services, big data analysis, and networks, an intelligent self-organized multi-agent system cannot be established. Kang et al. [17] stressed that cutting-edge ICT technologies are enablers and drivers of manufacturing's fourth revolution. Wan et al. [29] and Zhong et al. [30] agree that a myriad of useful data is needed in making a smart factory. Davis et al. [31] explained that SM will lead and respond to dramatic and fundamental business transformations to demand dynamic economies with IT-enabled smart factories. Ultimately, Smart Factory focuses on the shift on task-connected changes focusing not only profit but also flexibility and product output, together with further declining cost, reducing resource utilization, as well as a decrease in ecological impact.

Despite the hype towards Industry 4.0, smart manufacturing, and the Smart Factory concept, Canetta, Barni and Montini [32] have mentioned that numerous businesses have encountered challenges in implementing Industry 4.0. Rajnai and Kocsis [33] and Sony and Naik [1] indicated that some business owners are not clear on the current trend of industrial digitalization, and some leaders are clueless on how to implement it. Many manufacturing companies are still struggling to employ the SM concept [27,34-36]. With regards to the highlighted problems, readiness and maturity assessments have become an integral tool for the manufacturing enterprises, specifically for SMEs. A readiness model promotes the initialization of the development process. Since the business owner is uncertain about the consequence of Industry 4.0 technology [37], the readiness assessment is the right fit to diminish uncertainties on the invested technologies [38]. Readiness assessments typically conducted on a self-assessment basis that can be performed online or offline. In this self-assessment, the likely information gathered includes understanding, awareness, perception, current practice, as well as attitude of the organization.

To this date, many manufacturers are still exploring, working, and planning to boost their potentials so that they can stay relevant and face the market competition in time to come. In improving competitiveness, global manufacturing needs to empower themselves with technological breakthrough [17]. Rajnai and Kocsis [33] have commented that there is no rigid or standard model and commonly accepted methodology for measuring the adopters' Industry 4.0 readiness. Some readiness assessments are found to only focus on organizational Infrastructure Technology (IT) readiness [39-42]. Furthermore, the assessment outcome is often measured using various dimensions. Shifting to a smarter 
way of manufacturing practice involves high investment and changes in the organization's vision mission at the strategic level, as well as the modification of infrastructure and a new normal for the worker to adapt to. It does impact the Management, Machine, Method, and Man dimension in an organization. Choi, Jung and Lee [43] have also reported that a maturity assessment could enhance manufacturing companies' competitiveness.

Since moving into Industry 4.0 is directly correlated to the amount of investment an organization must make, this is risky, as failure is costly for the SME's. Prior to the implementation of SM, it is crucial for SMEs to assess the readiness of their manufacturing company's practice [44,45]. For instance, most SMEs in Malaysia are still in the adopting stage of modern technology under Industry 3.0 [46]. The adoptions of the Industry 4.0 concept are still at the infancy level among the small and medium enterprise (SMEs) [47]. Herewith, this paper is constructed to propose a readiness assessment model to help SMEs stimulate their journey in their implementation of SM. Schumacher et al. [38], in their industry-wide interview, have spotted problems in implementing Industry 4.0 in a manufacturing business, as follows:

- Failure of assessing Industry 4.0 readiness and capability is costly.

- Failure to understand the uncertainty of the technology implementation will directly influence its benefits and cost.

- Lack of strategic assistance and prior knowledge of the Industry 4.0 concept will tarnish the organization's development.

To this purpose, this paper addresses the type of readiness assessment needed to assist the SME's in understanding the mechanism towards adopting technological advancement and preparing SMEs to embark on the journey of SM and Industry 4.0. A readiness assessment model is derived based on the review findings. The developed mental model is expected to be used as a guide in developing a tailored readiness assessment for SMEs based in Malaysia. This research article therefore directed to find answers for the following research questions (RQ) from the review:

1. RQ1: Are the current assessment models best fit for SMEs?

2. RQ2: What is the assessment element in the current existing model that can be adapted to support SMEs?

3. RQ3: What is the study gap obtained from an existing model that is missing from an SME perspective?

This paper is organized as follows: Section 2 exhibits the Method section. Section 3 presents the critical review, and in Section 4, the findings obtained from the critical review are discussed, and therefore the conceptual framework is deliberated. The readiness assessment model is presented and discussed later in Section 4. Correspondingly, Section 5 exhibits the overall conclusion of this paper.

\section{Methodology}

This paper intends to pinpoint the conceptual framework from the review of existing readiness-maturity assessments and identify the gaps of the existing model, as well as propose a tailored model framework that is suitable for SMEs through a desk study of the relevant literature. The search was conducted in the powerful database such as Web of Science, Scopus, and Google Scholar, and the data are being compared among the subject literature from the secondary data from. Throughout this research work, "readiness assessment; maturity model; technology readiness" was consistently used as the keyword search. Empirical studies that evolve on the readiness and maturity model in the area of smart manufacturing and articles published in referred journals are all included in this study. The literature search disclosed four main criteria of an assessment models:

$\begin{array}{ll}\text { a } & \text { Dimension; } \\ \text { b } & \text { Measurement Approach; } \\ \text { c } & \text { Analytic Method; } \\ \text { d } & \text { Thrust. }\end{array}$


Both the conceptual framework and the mental model are derived from the fact findings. English language articles from renowned authors and reputable publishers located largely in Germany, the USA, Switzerland, South Korea, China, as well as other countries where the concept of SM correlates are analysed in this article. The methodology of this research work entails of a library search and an evaluation of the literature work on Industry 4.0, smart manufacturing, and readiness assessments. A thorough review of the current readiness assessment has enabled the author to address the drawback of current readiness assessment (Table A1 in Appendix A). Furthermore, a conceptual framework was derived to understand the mechanism of assessment logic. Different starting conditions for SMEs against the MNEs have blazed a new trail to enhance the existing framework tailored to SMEs. From the review, the assessment concept and dimension were identified that could be enhanced further to fit SMEs' requirements.

\section{Critical Review}

\subsection{Industry 4.0 Adaption in Malaysia}

In line with the global trend, the Industrial Revolution has spread to many countries, including Malaysia. In response to the Industry 4.0, or Fourth Industrial Revolution (4IR), the National Policy on Industry 4.0 was launched as Industry4WRD on 31 October 2018. Industry4WRD aims to boost the digital transformation of the manufacturing and related services sectors in Malaysia. The ultimate goal is for Malaysian manufacturers to be more robust through smart technologies. To this purpose, the Ministry of International Trade and Industry of Malaysia (MITI) has introduced various initiatives such as readiness assessments, intervention programmes, high-speed broadband connectivity to potential industrial parks, enhancing competence centres at public higher learning institutions, and reskilling programmes to address the technology and skills gaps among the industry players, especially for SMEs [48].

Nonetheless, the common challenges faced by Malaysia in the Industry 4.0 journey include the lack of understanding of the industry's best practices and failure in analyzing relevant information using case studies. In addition, there are also cases with the awareness deficiency to the need and impact of Industry 4.0 technologies, especially among SMEs, that reduces the chances of exploring opportunities and further disrupting their business models [49]. Other than that, it is reported that there is a shortage of the essential skills, knowledge, and talents for adopting Industry 4.0, especially in areas such as AI, IoT, robotics, and cybersecurity. Most importantly, the main drawback of Industry 4.0 implementation in Malaysia is the high adoption costs and a lengthier payback period [50].

Table 1 measures the different dimensions of the readiness in adopting digital technologies. Based on the GII index, Malaysia is still far from the best compared to its neighboring countries. Singapore seems to be the champion of the digitalization readiness in the ASEAN region. The lag behind the strong technology adopters is clearly seen when it comes to the digital adoption index for Malaysia. This supports the argument that Malaysia are still lacking behind and need progressive improvement to be the best among the best in the ASEAN region.

Table 1. Rankings of the ASEAN countries by their innovation and digitalisation readiness.

\begin{tabular}{|c|c|c|c|c|c|}
\hline \multirow{2}{*}{ Country } & \multirow{2}{*}{$\begin{array}{l}\text { Global Innovation } \\
\text { Index (GII) (Out of } \\
127 \text { Countries) }\end{array}$} & \multicolumn{2}{|c|}{$\begin{array}{l}\text { Readiness for the Future of Production } \\
\text { Assessment (Out of } 100 \text { Countries) }\end{array}$} & \multirow{2}{*}{$\begin{array}{l}\text { Networked Readiness } \\
\text { Index (NRI) (Out of } \\
139 \text { Countries) }\end{array}$} & \multirow{2}{*}{$\begin{array}{l}\text { Digital Adoption } \\
\text { Index (Out of } \\
180 \text { Countries) }\end{array}$} \\
\hline & & $\begin{array}{l}\text { Structure of } \\
\text { Production }\end{array}$ & $\begin{array}{l}\text { Drivers of } \\
\text { Production }\end{array}$ & & \\
\hline Singapore & 8 & 11 & 2 & 1 & 1 \\
\hline Malaysia & 35 & 20 & 22 & 31 & 41 \\
\hline Vietnam & 42 & 48 & 53 & 79 & 91 \\
\hline Thailand & 43 & 12 & 35 & 62 & 61 \\
\hline Philippines & 54 & 28 & 66 & 77 & 101 \\
\hline Indonesia & 85 & 38 & 59 & 73 & 109 \\
\hline Cambodia & 98 & 81 & 91 & 109 & 123 \\
\hline
\end{tabular}




\subsection{Small and Medium Enterprises (SMEs)}

A manufacturing-based SME in Malaysia is referred to the company in which their sales turnover is not exceeding RM 50 million or full-time employees are not exceeding 200 workers [50]. On the other hand, the sales turnover must not exceed RM 20 million or full-time employees not exceeding 75 workers for SMEs in the services and other sectors. In 2019, the Department of Statistic Malaysia (DOSM) [52] reported that the GDP for SMEs in Malaysia grew at $5.8 \%$ compared to $6.2 \%$. Nevertheless, the performance remained above Malaysia's GDP and non-SMEs, which registered $4.3 \%$ and $3.4 \%$ growths, respectively. The contribution of SMEs to the GDP increased to $38.9 \%$ from $38.3 \%$ in the previous year. The value-added of SMEs at constant 2015 prices were RM 552.3 billion as compared to RM 522.1 billion in 2018. In nominal terms, SMEs' GDP was recorded RM 586.9 billion in 2019 (2018: RM551.8 billion). Despite being the backbone of Malaysia's business environment, SMEs are relatively poor in digitalization [52]. Therefore, to promote the digitalization among SMEs in Malaysia, this paper proposes a readiness assessment model with the aim to provide a better guideline towards Industry 4.0's implementation. To this purpose, the existing readiness assessment model is thoroughly reviewed in the next section. The advantages and drawbacks of the existing model are analysed accordingly.

\subsection{Smart Manufacturing among SMEs and Readiness Assessment}

Numerous literatures have highlighted how SMEs cope and battle with technological sophistication. Over the decades, the competition among SMEs is felt locally and internationally [53]. In most condition, SMEs often support multinational companies. SMEs have to cope with unrelenting pressure from buyers and competitors to lower prices and accept diminishing sales margins [54]. In addition, they must also maintain their short delivery times with constant supply to avoid businesses loss. SMEs who upkeep with the technological advancement will have a brighter chance to survive, and those who are lacking will have to enhance themselves with the technological progress [54-56]. In most cases, these companies are not the early adopters of technological advancement [27]. This scenario must change, and SMEs need to leap forward and quickly learn to appreciate the emerging technologies and digital practices if they plan to stay relevant.

Mittal et al. [27] have mentioned in his work that there is still a low level of study focusing on SME entities related to smart manufacturing, technological adoption, and Industry 4.0. Many SMEs are aware of the concept of SM and Industry 4.0, but they do not know how and where to start. According to Sommer [57], SMEs are easily self-satisfied with what they have and ignore trends associated with digitalization and automation. The reluctancy of SME's invites urgency in research disparity within the current scientific body of knowledge. In helping the SMEs in leaping forward in technological digitalization, first the SMEs need to measure their readiness.

Readiness assessments or self-readiness assessments can be used as a guiding model to help the SMEs attain maturity in their explicit sphere and help them move in the right direction. According to Erol, Schumacher and Sihn [58], the existing maturity and readiness assessment model is established based on large companies' requirements rather than that of the SMEs'. Readiness assessment indices must not be too complex [59] and must be in favour to ensure that SMEs understand the detail of the assessment. A proper transformation plan and the measurement of their readiness index are in need to ensure a smooth transition towards successful transformation. Understanding user acceptance remains the first critical step in identifying readiness [60]. Readiness assessments typically occur before embarking on the transformation journey, while the maturity model used to assess that implies the progress in the process of adoption [38]. To date, there are many well-known readiness models for reference. Table A1 in the appendix describes the details of comprehensive SM and Industry 4.0 readiness assessment and maturity developed from 2014 to the latest one. Rockwell Automation was among the pioneer consultation companies who have proposed the Connected Enterprise Maturity Model. In other similar works, Lichtblau et al. [61] proposed IMPULS-Industrie 4.0 Readiness model. 
The readiness and maturity model shows an inclining trend, and each model presents unique dimensions and measurement criteria. Since there is no standard and perfectly consented model in this area $[1,37,40,58]$, the evidence of a research gap is distinctly observed [40].

\subsection{Review on the Conceptual Framework of Readiness and Maturity Model}

According to Basl [45], the readiness assessment and maturity model aids the organization in making fast decisions in addition to recommending the organization on the areas to improve. Maturity refers to the "state of being complete, perfect, or ready" [38,59], while readiness is commonly described as a state of being prepared of something. To date, several assessment models have been proposed by Academician, government organizations, private organizations, as well as consulting firms [62], and this assessment we constructed based on descriptive, prescriptive, or comparative purposes [32,63]. The readiness and maturity assessment consist of evaluating dimensions with scales to measure their readiness level. This model is commonly equipped with stages of maturity or readiness level. This readiness level depicts Level 1, which defines a dearth of the attribute, and level 5 represents an advanced level or required attribute [38].

In this work, 11 different mixed models from readiness to maturity model irrespective of any area and industries have been studied. All these models offer different dimensions, complexities, and depths with regards to their scope and methodology. This is again proof that no standard has been agreed upon in developing the maturity and readiness model. Table A1 reflects the comparative analysis of the published readiness and maturity model intended for SM and Industry 4.0. Several renowned model and tools are discussed in detail below.

Lichtblau et al. [61]: "IMPULS-Industrie 4.0 Readiness". This model is regarded as one of the most comprehensive and well-grounded readiness models. It consists of six dimensions for assessment: Information Technology, Organization strategy, Data Management, Factory, Employee, and Product. This assessment consists of six readiness levels, starting with 0-outsider, 1-beginner, 2-intermediate, 3-experience, 4-expert, and 5-top performer. The application's purpose is descriptive. The IMPULS readiness assessment is best fit to measure the readiness level of the manufacturing and engineering industries. This Industry 4.0 readiness model is an online self-assessed readiness model that suits medium to larger or large enterprises who intend to embark on the Industry 4.0 journey. With enabling the advance criteria of manufacturing technology in this assessment, SMEs would not score well and may often be left behind. SME readiness assessment outcomes will always be reflected as "outsiders".

Leyh et al. [64]: "System Integration Maturity Model Industry 4.0-SIMMI". This model focuses mostly in assessing the industrial internet maturity. Vertical integration (VI), Horizontal integration (HI), Digital product development, and Cross-sectional technology criteria are all included in the model dimension. This model evolves within five levels of maturity, starting from level 1 (basic digitalization level) to level 5 (optimized full digitalization). This model embraces the descriptive application purpose in developing the model. Most SMEs are not even near to the digitalization stage. Since SIMMI focuses more on VI and $\mathrm{HI}$ that reflects the real time integration, SMEs are more conventional in terms of their supply-chain rather than integrated due to financial constraints. Therefore, the VI and HI does not consider the SME's sensitivity.

Schumacher, Erol and Sihn [38]: "Maturity model for assessing Industry 4.0 readiness and maturity of manufacturing enterprises". The model includes nine dimensions, namely Products, Customer, Operation, Technology, Strategy, Leadership, Governance, Culture, and People. This model is based on the Maturity Model that employs descriptive purpose covering the manufacturing industries as their assessment scope. This model utilized five maturity levels (level 1-level 5), representing a lack of attributes to state-of-the-art attributes. Schumacher, Erol and Sihn [38], in their work, imply that a maturity index can calculate the readiness level of the industry. 
Gökalp, Sener and Eren [40]: "Industrie 4.0 Maturity model". This model consists of six maturity levels (incomplete, performed, managed, established, predictable, and optimizing) with a focus in five dimensions, namely, asset management, data governance, application management, process transformation, and organization alignment. This whole assessment is more focused on skill capability assessment. This model offers a comprehensive evaluation measure; nevertheless, this model did not mention fit for use by the small-medium enterprise. The authors of [40] also cited that no model would satisfy all criteria.

Malaysian International Trade and Industry [48]: "Industrial 4ward". The first-ever Malaysian Industry 4.0 readiness assessment focuses on manufacturing industries that cover three major shift factors, such as the dimension (people, process, and technology). Five types of readiness levels are adopted in this model (none, learner, experience, performance, and leader). Not much data is published in related to this assessment, as this assessment are handled in a close loop within appointed government agencies.

Rockwell Automation (2014) [65]: “The Connected Enterprise Maturity Model." With a greater focus on the information technology readiness, this model includes four dimensions (information infrastructure, controls devices, networks, and security policies). This model was reported to embrace five levels of maturity measure; nevertheless, not much detail was published on a related item. This model suggested that small-medium enterprises need to collaborate to archive the Industry 4.0 maturity level. This is an obvious point that all SMEs will be able to match up. The Rockwell model embedded the advance manufacturing technology in the measuring dimension that can lead to less participation by small-medium enterprises. This assessment tool offers less information about its development and detail process to the reader to judge further.

Akdil, Ustundag and Cevikcan [37]: "Maturity and readiness model for industry 4.0 strategy". Uses a scale from 0-3 to measure the level of maturity; absence, existence, survive, and matured. This method deploys three central dimensions, in which smart products and services, smart business, and organization strategy are all included in the model. This model covers both the manufacturing as well as the retail part. This model employs a descriptive purpose to complete the survey. These authors have compared several models [38,61-65] in their study. In this work, the suitability of this model to the small-medium enterprise is not mentioned.

Schuh et al. [66]: "Industrie 4.0 Maturity Index". This model deploys six levels of maturity level (computerize, connectivity, visibility, transparency, predictive capacity, and adaptability) with four dimensions (resources, information system, organization structure, and organizational culture). This model covers five functional areas in the business, which includes research and development, production, logistic, service, and marketing and sales. Digital transformation is the main motive of this maturity model. This model also includes advance manufacturing technology as part of the maturity index measurement. This model supports the concept of digitalization is the key enabler for Industry 4.0. The build-up of this model was based on consultation tools, and it is not a self-assessed tool. A company that plans to use this assessment is required to hire a consultant to assist them in the evaluation. Small industries that use this tool to measure maturity will find it costly, timely, and not suitable to cater to their business setup. This tool is more appropriate to be used by medium and large enterprises.

Gill et al. [39]: "Forrester digital maturity model 4.0". It is a benchmark tool to measure the digital business maturity of a company. This model uses four major dimensions to assess the digitization maturity (culture, technology, organization, insight). This model is distributed into four maturity levels in which the beginner is known as sceptics, adopters, and collaborators, and the highest level provided in this model is differentiators. This model is based on a comparative application purpose in approaching the subject of their assessment. This model offers less information on the usage of an industrial-based organization but emphasis more on e-business and e-commerce digital marketing and digital 
readiness capabilities. This model also provides an evaluation on how digital supports sales and service connections comprise touchpoint integration and technology complexity.

Botha [67]: "Future readiness for industry 4.0 ". Since the future cannot be predicted, a future thinking model was developed that encounters possible future, plausible future probable future, and preferred future. This model is based on the future thinking model within the future, shaping factors that have been translated into the readiness dimension. Technology, the behaviour of people, and events that may change the world are all included in the measuring element. Technological readiness level and manufacturing readiness level developed by the United States Department of Defence we used as motivation in developing its own ten levels of Technology future-readiness level [68]. In this model, there are also five levels of Behavioural future-readiness level and Enterprise behaviour future-readiness level. Additionally, there is also an event future-readiness level and future thinking readiness level both with 10 levels of readiness level. There is evidence that this model is conducted as per audit procedure and requires a third party to assess the outcome. The complexity of this model may lead to hinder small-medium enterprises from using this tool.

Qin, Liu and Grosvenor [69]: “A framework of manufacturing for Industry 4.0 and beyond". This model is a self-assessed tool that measures maturity in the five dimensions, namely, the single station automated cell, automated assembly system, flexible manufacturing system, computer integrated manufacturing, and reconfigurable manufacturing system. All these dimensions being tied up with 11 levels of a maturity gateway. This model offers the assessed the understanding of their current state and gap identification by employing a comparative purpose method. This model can be considered complicated to the most SMEs as small companies often hardly have more than two of these dimensions mentioned above. Hence, this model again belongs to the companies with a larger size group.

From the above-discussed model, it can be observed that vast majority of the model were produced in the last few years with diverse spectrum. The characteristic of the theoretical concepts of SM Industry 4.0 assessment model is the thrust, dimension, assessment analytic method, and the scale. The thrust in the assessment encompasses the organization's wide scope attribute, while the dimension covers the sub-attribute of the organization. Elsewhere, the assessment is tied up with an analytic method that represents the type of assessment. The descriptive-analytical way is more likely to reflect the readiness model, whereas the prescriptive and comparative analytic assessment approach is best to fit the maturity assessment model. Scaling the dimension capacity is a vital mechanism to measure the degree of maturity and readiness [45]. Each model has its measuring approach to reflect the overall organization level.

\section{Results and Discussion}

Through the critical review analysis, a set of gaps between the models have been drawn. Firstly, the existing model is aimed for Multinational Enterprises (MNEs). Most of them presume that the MNEs are the information technology (IT) expert users with the advanced and interconnected machines, to mention a few. Hence, rest assured that a substantial number of MNEs have already embarked on their journey towards SM. Whereas SMEs are on the contrary, and they are still lacking on the resources such as dedicated automated machines, IT experts, or even IT departments that may lead to the difficulties of implementation of the SM concept. It is vital to acknowledge that this extensive view on SMEs is not applicable for all SMEs in general. There are some high-tech, technology-based SMEs that can be viewed as role-models in the SM perspective. Nevertheless, according to Quinton and Simkin [70], the extensive view is substantiated and it is appropriate basis for the work presented in the current research.

In this view, it epitomizes that when an assessment is conducted, the MNEs will start with a presumptive readiness level scale "Experience" or "learner" or "Level 1" phase where the status of starting to implement and executing the SM and Industry 4.0. In contrast, SMEs need to start with "Level 0", or as "Newcomers", which reflects extremely limited or 
no adoption of technological or IT capability. Level 0 reflects the capabilities of SMEs on the know-how and ability to handle the technologies. From the aspect of upgrading the infrastructure and facilities, as well as people mindset, MNEs are more realistic to attain the shift in terms of IT facilities acquisition and human capital enhancement towards SM and Industry 4.0 compared to SMEs. The action plan execution is way too exponential to SMEs compared to MNE. This indicates that SMEs' and MNEs' starting conditions differ from each other. Finally, the measurement dimension assessed in the existing model (Table A1) are irrelevant to most SMEs.

For instance, Leyh et al. [64] included vertical and horizontal integration dimensions in their assessment tools. The assumption of digitally integrated SMEs may not be possible since the integration may need a huge investment of software that translates their business operation in real-time. SMEs are more open to a direct resource's management. The likely dimension that are more appropriate for SMEs are the Man, Machine, Method, and Management dimension. Thus, it validates the purpose of proposing a new assessment model for SMEs. If all these gaps are addressed appropriately, the proposed model can help SMEs to attain their journey to achieve Smart Manufacturing reputation.

\subsection{Conceptual Framework for the Industry 4.0 SM Readiness and Maturity Assessment}

From the analysis, a conceptual framework for the proposed Industry $4.0 \mathrm{SM}$ readiness and maturity model is built and shown in Figure 1. It can be concluded that the common mainstays digested from the available readiness and maturity model are people, technology, process, product, infrastructure, organization, and customer.

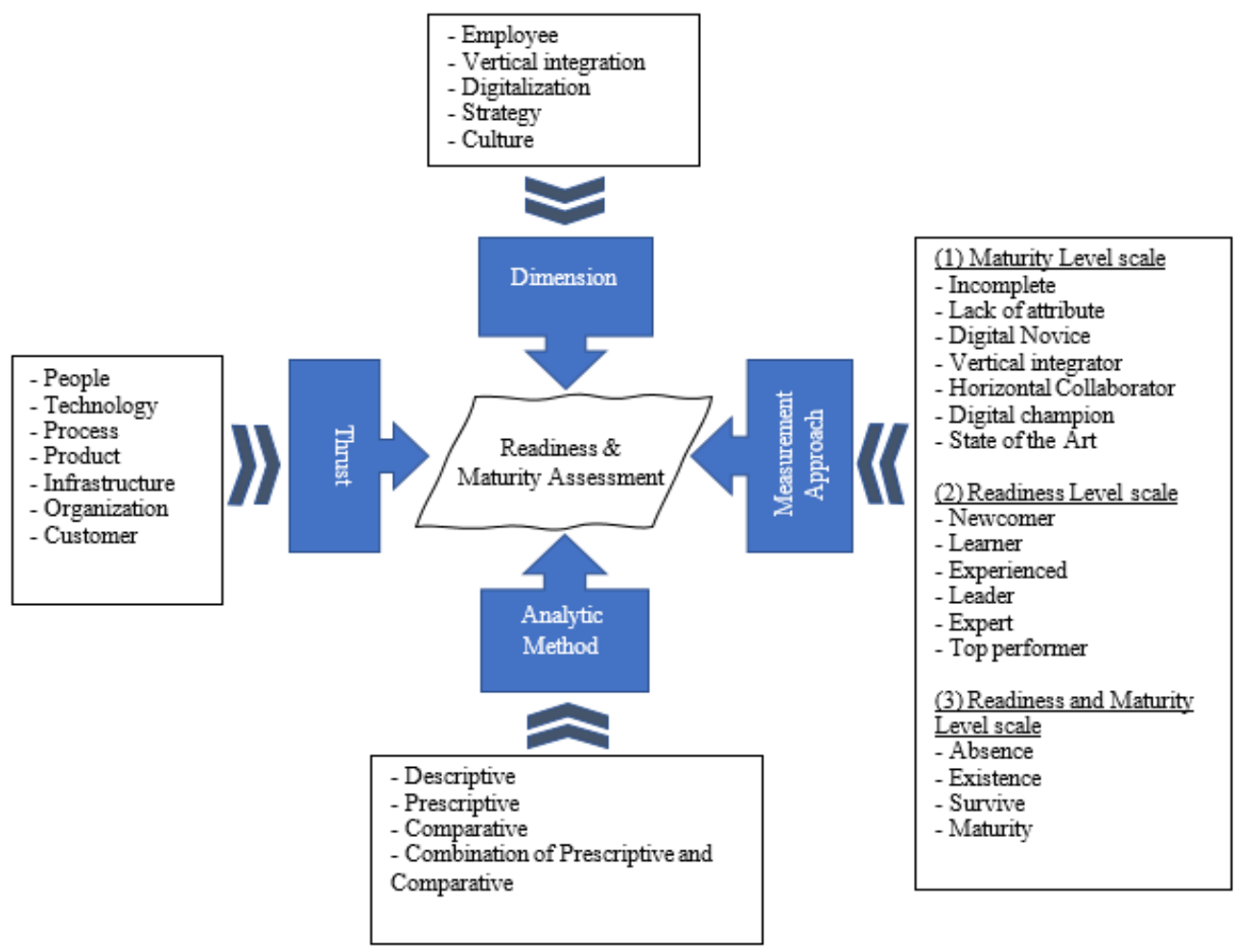

Figure 1. Conceptual framework of the industry 4.0 Smart Manufacturing readiness and maturity assessment.

Although most models encompass the above-said thrust, the conception varies among the models. For instance, one model may assess the people dimension; alongside people, a model tends to focus more on human resources capability while another assessment model may want to contain the training, culture, leadership, etc. In this context, all the attributes related to the mainstay are put into the sub-dimension section that will be translated to the primary needs of each assessment. Measuring the scale is to gauge the construct of the aim [71]. The scales determine the measurement approach used to quantify 
variables in performing data analysis. The existing maturity and readiness model employ three primary different measurement approaches in their assessment tools. There is a visible contrast between the maturity model scales compare to the readiness model due to the nature of the assessment. Nevertheless, the combination measurement approach can be observed in the maturity and readiness model.

The principle basis scale are predominantly based on the traditional conception of the maturity model [45]. De Carolis, Macchi, Negri [72], in their work, have summarised the main purpose of the analytic assessment method in the following three classifications: (i) descriptive analytic: a model that assess the current state of an organization situation; (ii) prescriptive analytic: assessment model that outcome distillates the maturity improvement; finally, (iii) comparative analytic: the model evolves on benchmarking crosswise companies to check their readiness and maturity.

\subsection{The Mental Model of Smart Manufacturing Readiness Assessment}

An uncertainty needs to be address in earlier stage [73]. An assessment model should clarify uncertainties rather than forming new ones [74]. Technological complexity in implementing smart manufacturing is not precisely defined [75]. The complexity of future system will lead to uncertainties that may impact the SMEs in their journey to embrace smart manufacturing practices. SMEs with the ability to master the technology of Industry 4.0 will have the edge to occupy the right position in the market [76]. Wiesner at al. [74] suggested that SMEs need a step-by-step guide to help them embrace the concept of Industry 4.0 and smart manufacturing. Therefore, focusing on the Man, Machine, Management, and Method will be the easiest thrust for the SMEs to perceive the journey of smart manufacturing. Simplicity is proposed to avoid an entry barrier for the SME's. Accordingly, based on the conceptual framework presented in the previous section, a mental model of the Industry 4.0 Smart Manufacturing readiness assessment for SME's is proposed as shown in Figure 2.

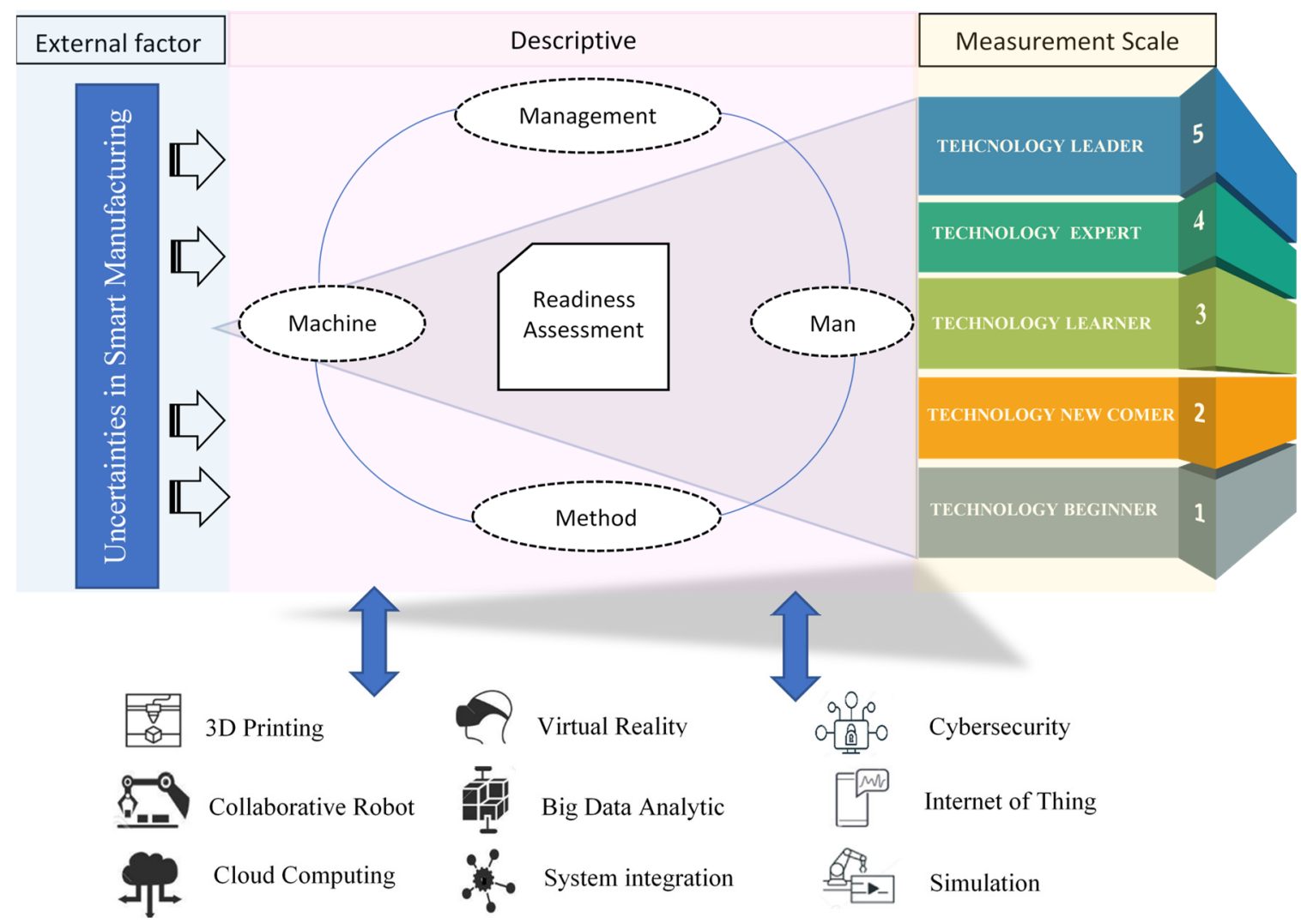

Figure 2. Proposed model framework of the industry 4.0 Smart Manufacturing readiness assessment for SME's. 
As shown in Figure 2, the proposed model exhibits the build mechanism of a more inclusive model than others, while incorporating external factors that directly evolve among the pillars in smart manufacturing. This model considers the uncertainties in smart manufacturing as the external factors that could affect the assessment. Five measurement scales are listed in complying with the model. Small businesses that attempt to measure their readiness using the existing tools designed for big companies have encountered difficulties [9]. Commonly, scales were established from the engineering viewpoint. Moreover, the emphasis is more on technological issues. The proposed scale is mainly adapted from the literature, and it assists small companies to work on the action in improving their readiness.

The proposed framework model is expected to help evaluate the companies' present readiness level to embrace the smart manufacturing methodology and system and recognize solid measures to help them capitalize on the benefits of Industry 4.0 initiatives. This work has proven that the existing model that measures maturity and readiness could not satisfy all industry needs. Thus, this tailored readiness assessment is projected to fulfil the needs and wants of SMEs. This model is expected to help small scale manufacturing entities identify the required technologies according to the process related to their business nature. In addition, this model will also provide the uncertainties list that each technology offers, in which it will be beneficial to the business owner in making decision on the right technologies to invest in. Although this paper focuses on the implementation of SMEs in Malaysia, the proposed model is expected to be also viable in other countries.

\section{Conclusions}

Industry 4.0 conceivably signifies the beginning of the Fourth Industrial Revolution. Despite the hype behind the idea of Industry 4.0, the common ground on understanding the core concept of Industry 4.0 needs to be suggested among the SMEs. Interest in Industry 4.0 and smart manufacturing is increasing day by day. Nevertheless, the importance given to small-medium enterprises is still at a low level. From the model and readiness assessment evaluation done, the evaluation dimension and maturity or readiness level criteria should be carefully evaluated. All these models are unique from their author's perspective; nevertheless, this model is considered generic. The existing models are most suited to large businesses due to the complexity of the assessment. Most of the models cover the dimension of strategy, culture, leadership, and human resources. From the literature, the common traits found that the present maturity model and readiness assessment are unique and differ from each other despite some common dimensions being re-mentioned. Technology domains are the most popular dimension used among the existing assessment models. Despite the regularity of using the term technology, the view of each model is diverse. Some models use information technology, some use manufacturing technology, and few use digital technology. There are also models referring to technology as digitization. This is because the facet is dynamic corresponding to the nature of the industries and needs. Some authors of the models share the development detail of their tool, but most remain unrevealed. As not much detail on the development process of the tools is shared, it indicates that the area is still unsaturated. Few tools are made available online for selfassessment, whereas some models are used as a consultancy tool in which a third-party consultant is required if a company needs to assess their company's maturity or readiness level. It will be economical for the SMEs to perform a self-assessment check on their readiness level rather than hiring a consultant.

Thus far, the evidence shows that there is a lack of sector-wide assessment models formed in the automotive, food, and chemistry sectors. therefore, this can trigger future research to explore the lacking sectors to close the gap. Each SME is unique with specific needs. Small businesses, in the future needs an enhanced assessment model that fit their needs, and it should be straight forward and easy to comprehend. Given the analysis result from the literature, to be focus oriented, a disjunct assessment model emphasis exclusively to a small business environment is required. The conceptual model should encounter all the drawbacks highlighted in this paper. A specific yet straightforward 
readiness model encompassing Man, Machine, Method, and Management is recommended to facilitate the small-medium enterprise to pave their ways in making their organization comply with smart manufacturing, and Industry 4.0 requirements are needed. Therefore, the proposed mental model is expected to help the SMEs in leaping forwards, achieving smart manufacturing status.

Author Contributions: Writing—original draft preparation, S.R.B.R.; Supervision, Z.L, B.T.H.T.B.B. and S.A.A.; project administration, Z.L. All authors contributed to all the sections and reviewed the manuscript. All authors have read and agreed to the published version of the manuscript.

Funding: This research was funded by Ministry of Education Malaysia, funding from SLAI “KPM(BS)830121075643”.

Data Availability Statement: Data is contained within the article.

Acknowledgments: Special thanks to Universiti Malaysia Pahang for the support given in making research work successful. Also, to mention, the authors are grateful to anonymous reviewers and editors for their constructive comments and suggestions on this article.

Conflicts of Interest: The authors declare no conflict of interest. 


\section{Appendix A}

Table A1. Comparison of Industry 4.0 readiness and maturity model.

\begin{tabular}{|c|c|c|c|c|c|c|c|}
\hline Model Name & Year & $\begin{array}{l}\text { Author/ } \\
\text { Source }\end{array}$ & $\begin{array}{l}\text { Assessment Approach } \\
\text { (Maturity Level) }\end{array}$ & Industry Covered & Assessment Mode & Dimension & Drawback \\
\hline Industrial 4ward & 2018 & [48] & $\begin{array}{l}\text { Assessment in } 3 \text { dimensions and } \\
\text { indicated readiness in } 5 \text { levels } \\
\text { (None, Newcomer, Learner, } \\
\text { Experienced, and Leader); focus } \\
\text { on efficiency and productivity }\end{array}$ & Manufacturing industry & $\begin{array}{l}\text { IR4.0 capability } \\
\text { assessment }\end{array}$ & People, Technology, Process & $\begin{array}{l}\text { All } 9 \text { pillars in Smart Manufacturing } \\
\text { are not being evaluated. Uncertainties } \\
\text { are not highlighted. Not much detail } \\
\text { published. }\end{array}$ \\
\hline $\begin{array}{l}\text { IMPULS-Industrie } 4.0 \\
\text { Readiness }\end{array}$ & 2015 & [61] & $\begin{array}{l}\text { Assessment in } 6 \text { dimensions and } \\
\text { indicate readiness in } 5 \text { levels } \\
\text { (Outsider, Beginner, Intermediate, } \\
\text { Experienced, Expert, Top } \\
\text { Performer) that divided into three } \\
\text { main categories (Newcomers, } \\
\text { Learners and Leaders) }\end{array}$ & $\begin{array}{c}\text { Not Specified. However, } \\
\text { based on the assessment } \\
\text { model, it is more } \\
\text { generic and suitable } \\
\text { generally to Medium to } \\
\text { Large manufacturing } \\
\text { industries }\end{array}$ & Maturity assessment & $\begin{array}{l}\text { IT, Organization Strategy, } \\
\text { Data Management, Factory, } \\
\text { Employee, Product }\end{array}$ & $\begin{array}{l}\text { Assessments are not specified to } \\
\text { Automotive industries. Suitable to a } \\
\text { medium to large scale business as the } \\
\text { complex terminology used are more } \\
\text { advance and not ideal to SMEs. All } 9 \\
\text { pillars in Smart Manufacturing are not } \\
\text { being evaluated. Uncertainties are not } \\
\text { highlighted; indicates minimal } \\
\text { suggestion to improve. }\end{array}$ \\
\hline $\begin{array}{l}\text { Industry 4.0/Digital } \\
\text { Operations } \\
\text { Self-Assessment }\end{array}$ & 2016 & [77] & $\begin{array}{c}\text { Online self-assessment in } 6 \\
\text { dimensions; focus on digital } \\
\text { maturity in } 4 \text { levels (Digital } \\
\text { Novice, Vertical integrator, } \\
\text { Horizontal collaborator, and } \\
\text { Digital Champion) }\end{array}$ & $\begin{array}{l}\text { Generic and suitable } \\
\text { generally to } \\
\text { manufacturing } \\
\text { industries }\end{array}$ & $\begin{array}{l}\text { Focus on Digital } \\
\text { Maturity assessment }\end{array}$ & $\begin{array}{l}\text { Business Model, Market and } \\
\text { Customer Access, Value } \\
\text { Chain and Processes, IT } \\
\text { Architecture, Legal, } \\
\text { Compliance and Tax, } \\
\text { Organization, and Culture }\end{array}$ & $\begin{array}{l}\text { It is a consultancy assessment tool. Fee } \\
\text { for assessment is required. The choice } \\
\text { of industry is available; nevertheless, } \\
\text { the evaluation is more generic and not } \\
\text { explicitly intended to specific } \\
\text { industries. Suitable to a medium to } \\
\text { large scale business as Complex } \\
\text { terminology used are advance and not } \\
\text { ideal to SME's. All } 9 \text { pillars in Smart } \\
\text { Manufacturing are not being } \\
\text { evaluated. Uncertainties are not } \\
\text { highlighted. }\end{array}$ \\
\hline $\begin{array}{l}\text { Future Readiness for } \\
\text { Industry } 4.0\end{array}$ & 2018 & [67] & $\begin{array}{l}\text { Uses } 5 \text { to } 10 \text { readiness maturity } \\
\text { levels. Each varies from one } \\
\text { another. }\end{array}$ & $\begin{array}{c}\text { Generic and suitable for } \\
\text { the general } \\
\text { manufacturing and } \\
\text { service industry. }\end{array}$ & $\begin{array}{l}\text { Based on a } \\
\text { future-readiness level } \\
\text { that measures future } \\
\text { opportunities. Focuses } \\
\text { more on the strategic } \\
\text { level that stimulated the } \\
\text { future thinking process. } \\
\text { Evolving (technology, } \\
\text { Behaviour and Event) }\end{array}$ & $\begin{array}{l}\text { Technology Future } \\
\text { Readiness, Market and } \\
\text { Enterprise behaviour } \\
\text { readiness, Event } \\
\text { future-readiness levels, } \\
\text { Future thinking readiness } \\
\text { levels }\end{array}$ & $\begin{array}{l}\text { Tools are too complicated to be used } \\
\text { by the SMEs. }\end{array}$ \\
\hline
\end{tabular}


Table A1. Cont.

\begin{tabular}{|c|c|c|c|c|c|c|c|}
\hline Model Name & Year & $\begin{array}{l}\text { Author/ } \\
\text { Source }\end{array}$ & $\begin{array}{l}\text { Assessment Approach } \\
\text { (Maturity Level) }\end{array}$ & Industry Covered & Assessment Mode & Dimension & Drawback \\
\hline SIMMI 4.0 & 2016 & [64] & $\begin{array}{l}\text { The model has five maturity } \\
\text { stages (Basic, Cross-department, } \\
\text { Horizontal and Vertical, Full } \\
\text { Digitization, and Optimized } \\
\text { Digitization) and four dimensions } \\
\text { of integration }\end{array}$ & Not specified & $\begin{array}{l}\text { System Integration } \\
\text { Maturity Model in the } \\
\text { context of IR } 4.0\end{array}$ & $\begin{array}{c}\text { Vertical Integration, } \\
\text { Horizontal Integration, } \\
\text { Digital Product, } \\
\text { Development, } \\
\text { Cross-sectional Technology } \\
\text { Criteria } \\
\end{array}$ & $\begin{array}{c}\text { They are focusing only on internet } \\
\text { maturity and system integration, only } \\
\text { without specifying a suitable industry. } \\
\text { Tools are not available for public } \\
\text { assessment. }\end{array}$ \\
\hline $\begin{array}{l}\text { Industrie } 4.0 \text { maturity } \\
\text { model }\end{array}$ & 2017 & [40] & $\begin{array}{l}\text { The model has six maturity levels } \\
\text { (Incomplete, Performed, Managed, } \\
\text { Established, Predictable, } \\
\text { Optimizing) and five dimensions } \\
\text { of capabilities }\end{array}$ & Not specified & $\begin{array}{l}\text { Capability assessment } \\
\text { of a company to achieve } \\
\text { IR4.0 }\end{array}$ & $\begin{array}{l}\text { Asset Management, Data } \\
\text { Governance, Application } \\
\text { Management, Process } \\
\text { Transformation, } \\
\text { Organization Alignment }\end{array}$ & $\begin{array}{l}\text { This maturity model focuses on the } \\
\text { capability assessment of a company to } \\
\text { achieve IR4.0. Tools are not available } \\
\text { for public evaluation. }\end{array}$ \\
\hline $\begin{array}{l}\text { The Connected } \\
\text { Enterprise Maturity } \\
\text { Model }\end{array}$ & 2014 & [65] & $\begin{array}{l}\text { Maturity model as part of a } \\
\text { 5-stage approach to realize } \\
\text { Industry 4.0; technology-focused } \\
\text { assessment in } 3 \text { dimensions }\end{array}$ & $\begin{array}{l}\text { Generic and suitable } \\
\text { generally to } \\
\text { manufacturing } \\
\text { industries }\end{array}$ & $\begin{array}{c}\text { Information Technology } \\
\text { and Operation } \\
\text { Technology readiness } \\
\text { Assessment }\end{array}$ & People, Process, Technology & $\begin{array}{l}\text { Not much detail about this assessment } \\
\text { tool as it is more of a consulting tool. } \\
\text { Tools are not available for public } \\
\text { assessment. }\end{array}$ \\
\hline $\begin{array}{l}\text { Industry } 4.0 \text { Readiness } \\
\text { and Maturity Model of } \\
\text { manufacturing } \\
\text { enterprise }\end{array}$ & 2016 & [38] & $\begin{array}{l}\text { Five maturity levels (level } 1 \\
\text { describes a complete lack of } \\
\text { attributes supporting the concepts } \\
\text { of Industry } 4.0 \text { and level } 5 \\
\text { represents the state-of-the-art) }\end{array}$ & $\begin{array}{l}\text { Manufacturing } \\
\text { enterprise }\end{array}$ & $\begin{array}{l}\text { Focuses on knowledge } \\
\text { sharing and } \\
\text { collaboration; ICT } \\
\text { competences, openness, } \\
\text { and autonomy of } \\
\text { employee; effective use } \\
\text { of mobile technologies }\end{array}$ & $\begin{array}{l}\text { Strategy, Leadership, } \\
\text { Customers, Product, } \\
\text { Operation, Culture, People, } \\
\text { Governance, Technology }\end{array}$ & $\begin{array}{l}\text { Models are not made available. } \\
\text { Validity and Reliability are not being } \\
\text { addressed. Using a questionnaire and } \\
\text { manual input in a software-assisted } \\
\text { medium to obtain the output. }\end{array}$ \\
\hline $\begin{array}{l}\text { Maturity and Readiness } \\
\text { Model for Industry } 4.0 \\
\text { Strategy }\end{array}$ & 2018 & [37] & $\begin{array}{l}\text { Employs } 4 \text { levels of maturity } \\
\text { measures; (Absence, Existence, } \\
\text { Survive and Maturity) }\end{array}$ & $\begin{array}{l}\text { Retail business and can } \\
\text { be used generally in all } \\
\text { manufacturing } \\
\text { industries. }\end{array}$ & $\begin{array}{l}\text { It is a mix maturity } \\
\text { model that covers the } \\
\text { manufacturing and } \\
\text { retail part of the } \\
\text { readiness }\end{array}$ & $\begin{array}{l}\text { Smart Product and services, } \\
\text { Smart Business Process, } \\
\text { Strategy and Organization }\end{array}$ & $\begin{array}{l}\text { It is more service focused. Suitable for } \\
\text { the retail and service industry. } \\
\text { Nonetheless, it still can be used for the } \\
\text { manufacturing industry. Not covering } \\
\text { all nine pillars in IR 4.0. }\end{array}$ \\
\hline $\begin{array}{l}\text { Forrester digital } \\
\text { maturity model } 4.0\end{array}$ & 2016 & [39] & $\begin{array}{l}\text { Measures the digital business } \\
\text { maturity in four levels (skeptics, } \\
\text { adopters, collaborators, } \\
\text { differentiators) }\end{array}$ & Not specified & $\begin{array}{l}\text { Measures the digital } \\
\text { business maturity }\end{array}$ & $\begin{array}{l}\text { Culture, Technology, } \\
\text { Organization, Insight }\end{array}$ & $\begin{array}{l}\text { Focuses only on digital readiness and } \\
\text { digital marketing or eCommerce. }\end{array}$ \\
\hline
\end{tabular}




\section{References}

1. Sony, M.; Naik, S. Key ingredients for evaluating Industry 4.0 readiness for organizations: A literature review. Benchmarking Int. J. 2019, 27, 2213-2232. [CrossRef]

2. Fonseca, L.M. Industry 4.0 and the digital society: Concepts, dimensions and envisioned benefits. Proc. Int. Conf. Bus. Excell. 2018, 12, 386-397. [CrossRef]

3. Georgakopoulos, D.; Jayaraman, P.P.; Fazia, M.; Villari, M.; Ranjan, R. Internet of Things and Edge Cloud Computing Roadmap for Manufacturing. IEEE Cloud Comput. 2016, 3, 66-73. [CrossRef]

4. Lin, F.; Chen, C.; Zhang, N.; Guan, X.; Shen, X. Autonomous Channel Switching: Towards Efficient Spectrum Sharing for Industrial Wireless Sensor Networks. IEEE Internet Things J. 2016, 3, 231-243. [CrossRef]

5. Lom, M.; Pribyl, O.; Svitek, M. Industry 4.0 as a part of smart cities BT-016. In Proceedings of the Smart Cities Symposium Prague, SCSP 2016, Prague, Czech Republic, 26-27 May 2016; pp. 2-7. [CrossRef]

6. Lu, Y. Industry 4.0: A survey on technologies, applications and open research issues. J. Ind. Inf. Integr. 2017, 6, 1-10. [CrossRef]

7. Zheng, P.; Wang, H.; Sang, Z.; Zhong, R.Y.; Liu, Y.; Liu, C.; Mubarok, K.; Yu, S.; Xu, X. Smart manufacturing systems for Industry 4.0: Conceptual framework, scenarios, and future perspectives. Front. Mech. Eng. 2018, 13, 137-150. [CrossRef]

8. Tao, F.; Qi, Q.; Liu, A.; Kusiak, A. Data-driven smart manufacturing. J. Manuf. Syst. 2018, 48, 157-169. [CrossRef]

9. Mittal, S.; Khan, M.A.; Purohit, J.K.; Menon, K.; Romero, D.; Wuest, T. A smart manufacturing adoption framework for SMEs. Int. J. Prod. Res. 2019, 58, 1555-1573. [CrossRef]

10. Lin, T.C.; Wang, K.J.; Sheng, M.L. To assess smart manufacturing readiness by maturity model: A case study on Taiwan enterprises. Int. J. Comput. Integr. Manuf. 2020, 33, 102-115. [CrossRef]

11. Fatorachian, H.; Kazemi, H. The Management of Operations A critical investigation of Industry 4.0 in manufacturing: Theoretical operationalisation framework. Prod. Plan. Control. 2018, 7287, 1-12. [CrossRef]

12. Monostori, L.; Kádár, B.; Bauernhansl, T.; Kondoh, S.; Kumara, S.; Reinhart, G.; Sauer, O.; Schuh, G.; Sihn, W.; Ueda, K. Cyber-physical systems in manufacturing. CIRP Ann. 2016, 65, 621-641. [CrossRef]

13. Nick, G.; Szaller, Á.; Bergmann, J.; Várgedo, T. Industry 4.0 readiness in Hungary: Model, and the first results in connection to data application. IFAC Pap. OnLine 2019, 52, 289-294. [CrossRef]

14. Öberg, C.; Graham, L. How Smart Cities will Change Supply Chain Management: A Technical Viewpoint. Prod. Plan. Control. 2016, 27, 529-538. [CrossRef]

15. Heavin, C.; Power, D.J. Challenges for digital transformation-Towards a conceptual decision support guide for managers. J. Decis. Syst. 2018, 27, 1-14. [CrossRef]

16. Lasi, H.; Kemper, H.G.; Feltke, P.; Feld, T.; Hoffmann, M. Industry 4.0 in Business \& Information System Engeineering. Bus. Inf. Syst. Eng. 2014, 6, 239-242. [CrossRef]

17. Kang, H.S.; Lee, J.Y.; Choi, S.; Kim, H.; Park, J.H.; Son, J.Y.; Kim, B.H.; Noh, S.D. Smart manufacturing: Past research, present findings, and future directions. Int. J. Precis. Eng. Manuf. Green Technol. 2016, 3, 111-128. [CrossRef]

18. Walker, M. Reassessing Digital: The Culture and Process Change Imperative. Harv. Bus. School Publ. 2018, 14. Available online: https:/ / www.redhat.com/cms/managed-files/cm-harvard-business-review-digital-transformation-pulse-survey-f1 4828-201811-en.pdf (accessed on 25 March 2020).

19. Kagermann, H.; Wahlster, W.; Helbig, J. Securing the future of German manufacturing industry: Recommendations for implementing the strategic initiative INDUS-TRIE 4.0. Final Rep. Ind. 2013, 4. Available online: https:// docplayer.net/254711-Securing-thefuture-of-german-manufacturing-industry-recommendations-for-implementing-the-strategic-initiative-industrie-4-0.html (accessed on 15 January 2020).

20. Erboz, G. How to Define Industry 40: The Main Pillars of Industry 4.0. In Proceedings of the Conference: Managerial Trends in the Development of Enterprises in Globalization Era, Nitra, Slovakia, 1-2 June 2017; pp. 761-767.

21. Jones, M.; Zarzycki, L.; Murray, G. Does industry 4.0 pose a challenge for the SME machine builder? A case study and reflection of readiness for a UK SME. IFIP Adv. Inf. Commun. Technol. 2019, 530, 183-197. [CrossRef]

22. Machado, C.G.; Winroth, M.P.; Ribeiro da Silva, E.H.D. Sustainable manufacturing in Industry 4.0: An emerging research agenda. Int. J. Prod. Res. 2019, 1-23. [CrossRef]

23. Piccarozzi, M.; Aquilani, B.; Gatti, C. Industry 4.0 in management studies: A systematic literature review. Sustainability 2018, 10, 3821. [CrossRef]

24. Rüßmann, M.; Lorenz, M.; Gerbert, P.; Waldner, M.; Justus, J.; Engel, P.; Harnisch, M. Industry 4.0: The Future of Productivity and Growth in Manufacturing Industries. Bost. Consult. Group 2015, 9, 54-89. [CrossRef]

25. Vaidya, S.; Ambad, P.; Bhosle, S. Industry 4.0-A Glimpse. Procedia Manuf. 2018, 20, 233-238. [CrossRef]

26. Esmaeilian, B.; Behdad, S.; Wang, B. The evolution and future of manufacturing: A review. J. Manuf. Syst. 2016, 39, 79-100. [CrossRef]

27. Mittal, S.; Khan, M.A.; Romero, D.; Wuest, T. A critical review of smart manufacturing \& Industry 4.0 maturity models: Implications for small and medium-sized enterprises (SMEs). J. Manuf. Syst. 2018, 49, 194-214. [CrossRef]

28. Wang, S.; Wan, J.; Zhang, S.; Li, D.; Zhang, C. Towards smart factory for industry 4.0: A self-organized multi-agent system with big data based feedback and coordination. Comput. Netw. 2016, 101, 158-168. [CrossRef] 
29. Wan, J.; Yi, M.; Li, D.; Zhang, C.; Wang, S.; Zhou, K. Mobile services for customization manufacturing systems: An example of industry 4.0. IEEE Access 2016, 4, 8977-8986. [CrossRef]

30. Zhong, R.Y.; Xu, C.; Chen, C.; Huang, G.Q. Big Data Analytics for Physical Internet-based intelligent manufacturing shop floors. Int. J. Prod. Res. 2017, 55, 2610-2621. [CrossRef]

31. Davis, J.; Edgar, T.; Porter, J.; Bernaden, J.; Sarli, M. Smart manufacturing, manufacturing intelligence and demand-dynamic performance. Comput. Chem. Eng. 2012, 47, 145-156. [CrossRef]

32. Canetta, L.; Barni, A.; Montini, E. Development of a Digitalization Maturity Model for the Manufacturing Sector. In Proceedings of the 2018 IEEE International Conference on Engineering, Technology and Innovation (ICE/ITMC), Stuttgart, Germany, 17-20 June 2018; IEEE: Piscataway, NJ, USA, 2018; pp. 1-7. [CrossRef]

33. Rajnai, Z.; Kocsis, I. Assessing the Industry 4.0 Readiness of A Certain Industry. In Proceedings of the 2018 IEEE 16 th World Symposium on Applied Machine Intelligence and Informatics, Košice, Slovakia, 7-10 February 2018; IEEE: Piscataway, NJ, USA, 2018; pp. 225-230.

34. Sevinç, A.; Gür, Ş.; Eren, T. Analysis of the difficulties of SMEs in industry 4.0 applications by analytical hierarchy process and analytical network process. Processes 2018, 6, 264. [CrossRef]

35. Wuest, T.; Schmid, P.; Lego, B.; Bowen, E. Overview of Smart Manufacturing in West Virginia; Bureau of Business \& Economic Research and Industrial and Management Systems Engineering; College of Business and Economics, West Virginia University: Morgantown, WV, USA, 2018.

36. Masood, T.; Sonntag, P. Industry 4.0: Adoption challenges and benefits for SMEs. Comput. Ind. 2020, 121, 103261. [CrossRef]

37. Akdil, K.Y.; Ustundag, A.; Cevikcan, E. Maturity and Readiness Model. for Industry 4.0 Strategy. In Industry 4.0: Managing the Digital Transformation; Springer Series in Advanced Manufacturing; Springer: Cham, Switzerland, 2018. [CrossRef]

38. Schumacher, A.; Erol, S.; Sihn, W. A Maturity Model for Assessing Industry 4.0 Readiness and Maturity of Manufacturing Enterprises. Procedia CIRP 2016, 52, 161-166. [CrossRef]

39. Gill, M.; VanBoskirk, S.; Evans, P.F.; Nail, J.; Causey, L.G. The Digital Maturity Model 4.0. Forrester Res. 2016. Available online: https:/ / dixital.cec.es/wp-content/uploads/presentacions/presentacion06.pdf (accessed on 14 January 2020).

40. Gökalp, E.; Sener, U.; Eren, E. Towards the Development of a Testing in Automotive SPICE and TestSPICE: Synergies and Benefits. Int. Conf. 2017, 1, 30-42. [CrossRef]

41. Leyh, C.; Martin, S.; Schaffer, T. Industry 4.0 and Lean Production-A matching relationship? An analysis of selected Industry 4.0 models. In Proceedings of the 2017 Federated Conference on Computer Science and Information Systems (FedCSIS), Prague, Czech Republic, 3-6 September 2017; Volume 11, pp. 989-993. [CrossRef]

42. Menon, K.; Kärkkäinen, H.; Lasrado, L.A. Towards a maturity modeling approach for the implementation of industrial internet. In Proceedings of the 20th Pacific Asia Conference on Information Systems (PACIS 2016), Chiayi, Taiwan, 27 June-1 July 2016; Association for Information Systems: Atlanta, GA, USA, 2016.

43. Choi, S.; Jung, K.; Lee, J.Y. Development of an assessment system based on manufacturing readiness level for smart manufacturing and supplier selection. Int. J. Comput. Appl. Technol. 2017, 56, 87-98. [CrossRef]

44. Mittal, S.; Romero, D.; Wuest, T. Towards a Smart Manufacturing Toolkit for SMEs Towards a Smart Manufacturing Toolkit for SMEs. In Proceedings of the 15th International Conference on Product Lifecycle Management, Turin, Italy, 2-4 July 2018; Volume IFIP, AICT 540. Springer: Cham, Switzerland; pp. 476-487.

45. Basl, J.; Doucek, P. A Metamodel for Evaluating Enterprise Readiness in the Context of Industry 4.0. Information 2019, 10, 89. [CrossRef]

46. Abod, S.G. Industry 4.0: Are Malaysian SMEs Ready? BizPulse 2016, 17, 1-3.

47. Matt, D.; Modrák, V.; Zsifkovits, H. Industry 4.0 for SMEs Challenges, Opportunities and Requirements: Challenges, Opportunities and Requiremen; Palgrave Macmillan: London, UK, 2020. [CrossRef]

48. Ministry of International Trade and Industry. Industry 4WRD: National Policy on Industry 4.0; Ministry of International Trade and Industry: Kuala Lumpur, Malaysia, 2018.

49. TIskandar, T.M.; Hassan, N.H. Board Quality of SMESs in Malaysia: The Governing Role of Family Ownership. Procedia Econ. Financ. 2015, 31, 611-617. [CrossRef]

50. Hamidi, S.R.; Aziz, A.A.; Shuhidan, S.M.; Aziz, A.A.; Mokhsin, M. SMEs maturity model assessment of IR4.0 digital transformation. Adv. Intell. Syst. Comput. 2018, 739, 721-732. [CrossRef]

51. Castañeda-Navarrete, J.; Leal-Ayala, D.; Lopez-Gomez, C.; Palladino, M. Adaptation and Adoption of Industry 4.0 in Cambodia; United Nations Development Programme: New York, NY, USA, 2020.

52. Department of Statistics Malaysia. Press Release Small and Medium Enterprises (SMEs) Performance; Department of Statistics Malaysia: Kuala Lumpur, Malaysia, 2018-2020. Available online: https:/ /www.dosm.gov.my/ (accessed on 15 February 2021).

53. Abdullah, R.; Lall, M.K.; Tatsuo, K. Supplier Development Framework in the Malaysian Automotive Industry: Proton's Experience. Int. J. Econ. Manag. 2008, 2, 29-58.

54. Aruna, H.A.M. Technology Innovation for SME Growth: A Perception for the Emerging Economies. J. Econ. Sustain. Dev. 2013, 4, 156-163.

55. Oyeku, O.; Oduyoye, O.; Elemo, G.; Akindoju, F.; Karimu, F. Entrepreneurial Capability and Entrepreneurial Success of Small and Medium Enterprises: A Review of Conceptual and Theoretical Framework. Res. Humanit. Soc. Sci. 2014, 4, 136-144. 
56. Rahman, N.A.; Yaacob, Z.; Radzi, R.M. An Overview of Technological Innovation on SME Survival: A Conceptual Paper. Procedia Soc. Behav. Sci. 2016, 224, 508-515. [CrossRef]

57. Sommer, L. Industrial revolution-Industry 4.0: Are German manufacturing SMEs the first victims of this revolution? J. Ind. Eng. Manag. 2015, 8, 1512-1532. [CrossRef]

58. Erol, S.; Schumacher, A.; Sihn, W. Strategic guidance towards Industry 4.0-A three-stage process model. In Proceedings of the International Conference on Competitive Manufacturing, Stelenbosch, South Africa, 27-29 January 2016; pp. 495-501.

59. Wiesner, S.; Gaiardelli, P.; Gritti, N.; Oberti, G. Maturity Models for Digitalization in Manufacturing-Applicability for SMEs. Adv. Prod. Manag. Syst. 2018, 1, 81-88. [CrossRef]

60. Lin, J.C.; Chang, H.C. The role of technology readiness in self-service technology acceptance. Manag. Serv. Qual. Int. J. 2011, 21, 424-444. [CrossRef]

61. Lichtblau, L.K.; Stich, V.; Bertenrath, R.; Blum, M.; Bleider, M.; Millack, A.; Schmitt, K.; Schmitz, E.; Schröter, M. IMPULS-Industrie 4.0 Readiness; IMPULS: New York, NY, USA, 2015.

62. Sheen, D.; Yang, Y. Assessment of Readiness for Smart Manufacturing and Innovation in Korea. In Proceedings of the 2018 IEEE Technology and Engineering Management Conference (TEMSCON), Evanston, IL, USA, 28 June-1 July 2018; IEEE: Piscataway, NJ, USA, 2018.

63. De Carolis, A.; Macchi, M.; Kulvatunyou, B.; Brundage, M.P. Maturity Models and Tools for Enabling Smart Manufacturing Systems: Comparison and reflections for future developments. Adv. Prod. Manag. Syst. 2017, 514, 13-20.

64. Leyh, C.; Bley, K.; Schaffer, T.; Forstenhausler, S. SIMMI 4.0-A maturity model for classifying the enterprise-wide it and software landscape focusing on Industry 4.0. In Proceedings of the 2016 Federated Conference on Computer Science and Information Systems (FedCSIS), Gdansk, Poland, 11-14 September 2016; Volume 8, pp. 1297-1302. [CrossRef]

65. Rockwell Automation. The Connected Enterprise Maturity Model. Ind. Conectada 4.0 2014, 1-12. Available online: http: / / www.impulsstiftung.de/documents/3581372/4875835/Industrie+4.0+Readniness+IMPULS+Studie+Oktober+2015 .pdf/447a6187-9759-4f25-b186-b0f5eac69974 (accessed on 21 April 2020). [CrossRef]

66. Schuh, G.; Anderl, R.; Dumitrescu, R.; Krüger, A.; Hompel, M. Industrie 4.0 Maturity Index. Managing the Digital Transformation; Acatech Study: Munich, Germany, 2017.

67. Botha, A.P. Rapidly arriving futures: Future readiness for industry 4.0 a.p. Botha 1,2* article info. S. Afr. J. Ind. Eng. 2018, 29, 148-160.

68. Straub, J. In search of technology readiness level (TRL) 10. Aerosp. Sci. Technol. 2015, 1, 1-9. [CrossRef]

69. Qin, J.; Liu, Y.; Grosvenor, R. A Categorical Framework of Manufacturing for Industry 4.0 and beyond. Procedia CIRP 2016, 52, 173-178. [CrossRef]

70. Quinton, S.; Simkin, L. The Digital Journey: Reflected Learnings and Emerging Challenges. Int. J. Manag. Rev. 2017, 19, 455-472. [CrossRef]

71. Nelson, D.A.; Robinson, C.C.; Hart, C.H.; Anthony, D.; Marshall, S.J. Italian Preschoolers' Peer-status Linkages with Sociability and Subtypes of Aggression and Victimization. Soc. Dev. 2010, 19, 4. [CrossRef]

72. De Carolis, A.; Macchi, M.; Negri, E.; Terzi, S. A Maturity Model for Assessing the Digital Readiness of Manufacturing Companies. Adv. Prod. Manag. Syst. 2017, 513, 13-20. [CrossRef]

73. Pinilla, L.S.; Rodríguez, R.L.; Gandarias, N.T.; de Lacalle, L.N.L.; Farokhad, M.R. TRLs 5-7 advanced manufacturing centres, practical model to boost technology transfer in manufacturing. Sustainability 2019, 11, 4890. [CrossRef]

74. Wiesner, S.; Gaiardelli, P.; Gritti, N.; Oberti, G. Maturity Models for Digitalization in Manufacturing-Applicability for SMEs. In IFIP International Conference on Advances in Production Management Systems; Moon, I., Lee, G., Park, J., Kiritsis, D., von Cieminski, G., Eds.; Springer: Cham, Switzerland, 2018; Volume 536. [CrossRef]

75. Magruk, A. Uncertainty in the Sphere of the Industry 4.0-Potential Areas to Research. Bus. Manag. Educ. 2016, 14, $275-291$. [CrossRef]

76. Gudanowska, A.E. Technology mapping as a method of technology analysis in the light of selected foreign experiences. Econ. Manag. 2014, 6, 265-281. [CrossRef]

77. Geissbauer, R.; Vedso, J.V.; Schrauf, S. E Industry 4.0/Digital Operations Self-Assessment; PricewaterhouseCoopers: London, UK, 2016. 